lung in den Tagesablauf einzubinden. Auch eine niedrige Effizienz oder ein später Wirkeintritt der Therapie, ebenso wie eine unangenehme Galenik der eingesetzten Topika oder Nebenwirkungen wie Hautreaktionen beeinträchtigen die Adhärenz.

Vor Therapiebeginn sollte der Arzt sich Zeit für den Patienten nehmen, auf die individuellen Bedürfnisse eingehen und auch das Ausmaß der zu erwartenden Verbesserung realistisch besprechen. Wichtig sei ein frühzeitiger Therapiebeginn sowie eine effektive Kombinationstherapie mit einem schnellen Wirkeintritt und einem geringen Risiko für Rückfälle, sagte Aschoff. Ein einfaches Therapieschema und der Einsatz von effektiven, schnell wirksamen Fixkombinationen steigere die Adhärenz.

Angelika Bauer-Delto

Vortrag "Hau(p)tproblem Akne: Eine tägliche Herausforderung in der Praxis" von Dr. Roland Aschoff, 18. März 2017

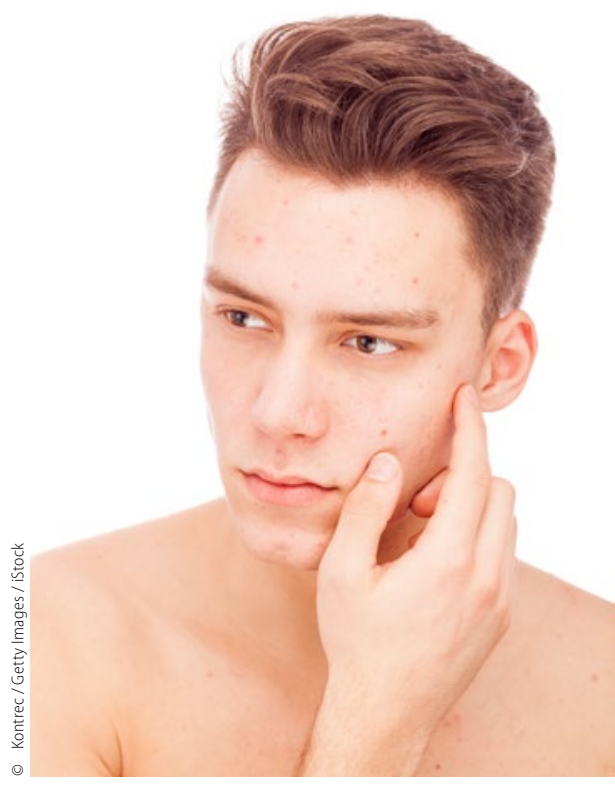

kongress

\title{
Dermatokosmetika bei Akne: Was ist empfehlenswert?
}

Zur Besserung der Lebensqualität bei der Akne tragen auch therapiebegleitende Dermatokosmetika bei, betonte Prof. Martina Kerscher, Universität Hamburg. Um zu verhindern, dass der Erfolg der Therapie durch ungeeignete Kosmetika zunichte gemacht wird, sollte der Hautarzt ein Kosmetikkonzept empfehlen und seinem Patienten am besten in schriftlicher Form mitgeben.

Die Haut sollte zweimal täglich mit alkalifreien Syndets gereinigt werden. Für die tägliche Hautpflege sollten Hydrogele oder leichte Öl-in-Wasser-Emulsionen verwendet werden. Hierfür können eine Reihe evidenzbasierter Inhaltsstoffe empfohlen werden. Keratolytische Inhaltsstoffe sind sinnvoll bei leichter Acne comedonica oder in der Erhaltungstherapie. Dazu zählen Salicylsäure sowie Milchsäure, die zudem einen hydratisierenden Effekt aufweist. Vorteil gegenüber der Glykolsäure sei, dass beide Substanzen nicht photosensibilisierend sind, so Kerscher. Nicht verschreibungspflichtiges Retinol und Retinsäure-Ester in Kosmetika kön- nen im Gegensatz zu Retinoiden auch in der Schwangerschaft eingesetzt werden. Niacinamid verringert infolge der Wirksamkeit auf die Barriereenzyme eine Seborrhoe und ist gleichzeitig hydratisierend. Günstig in Kosmetika sind auch sebumabsorbierende Partikel wie Tonerde, Zinkoxid oder Titanoxid, um den störenden Fettglanz zu mildern. Antibakteriell wirksame Peptide in Kosmetika helfen Propionibacterium acnes zu bekämpfen, auch wenn diese Antibiotika-Resistenzen aufweisen.

Dekorative Kosmetik trägt dazu bei, die Zeit bis zum Wirkeintritt der Akne-Therapie zu überbrücken und ist auch bei Postaknezuständen sinnvoll, sagte Kerscher.

Ein chemisches Peeling sowie eine Mikrodermabrasion oder ein Microneedling bei Aknenarben können in der Hautarztpraxis ergänzend angeboten werden. Angelika Bauer-Delto

Vortrag „Dermatokosmetische Therapieoptionen bei Akne: Update 2017“ von Prof. Martina Kerscher, 18. März 2017

\section{Hier steht eine Anzeige.}

